\title{
Individual and Corporate Users in IT Product Development Process
}

\author{
Malgorzata Pankowska \\ University of Economics, Katowice-Poland
}

\begin{abstract}
The rise of the Internet has increased the business transformation. On one hand, companies want to communicate with customers and partners in realtime. On the other hand, Internet users demand speedy, well-fitted access to actual information as well as to business applications. The paper focuses on user participation in the development of business information system (BIS). The paper covers review of different approaches on user involvement in the system development process. The second part of the paper includes the analysis of the empirical research results on user support software preferences.
\end{abstract}

\section{Introduction}

Encouraging users to be value creators in IT development processes is an important step in the competitive effectiveness increase activity. Nowadays, the problem is who is an user. Shapiro argues that in e-economy the focus on users instead of customers is necessary [16]. Users are employees working with business applications, but also customers, Internet websites reviewers, job candidates, business prospects and partners, brand fans, media members and other stakeholders, who interact with a company through digital media and Internet technology.

According to Claycomb et al. [9] users can actively participate in creating solutions, when IT service failures occur, by applying specialized skills and knowledge. For example, a user can diagnose his laptop problems based on the product's user manual. Shapiro is adding that today's customers have a strong self-service mentality - they want to be able to do everything themselves and solve their problems without professional intervention [16]. On the other side, they have a strong full-service mentality - when self-service fails, they demand immediate, personal support with a real person.

Generally, user is a person using IT services on a day-to-day basis within the business. This means that IT staff needs to be involved in the development and production of appropriate and relevant IT service level management procedures for Service Level Requirements (SLRs) and Agreements (SLAs) that detail the business quality targets, together with required business functionality.

Research on user participation so far has focused on how to employ users to increase productivity in the service delivery context. The purpose of this paper is to bridge the gap in the literature by investigating user participation in IT development processes and to present some suggestions in users' future co-creative behaviours. The paper is to show that nowadays users are no longer passive audience, but under certain circumstances they are active coproducers. The computer-literate users are observed as able to develop simple software applications to increase their personal productivity. User applications development has evolved to include complex application development by groups of users and share across departmental boundaries. However, there still prevails a common opinion that users applications are not significant, but rather transient and disposable as not production-oriented.

The main goal of the paper is to explain the role of users in the business information system exploitation and development processes. The paper consists of two main parts. The first part covers analysis of the works from other researchers on user innovativeness and their participation in system development. The second part includes considerations connected with empirical research on the user willingness to utilize software tools to support their business system development and exploitation.

\section{User involvement in BIS development process}

Historically, there are several kinds of adaptive methodologies of information system development that build a model of users' knowledge and their involvement in the development process. Prahalad and Ramaswany presented a co-creation model based on dialogue, access, risk reduction and transparency of information exchange between users and software company [15]. Von Hippel developed the lead user approach and he says that some users are more appropriate to co-develop new products and services than others [20]. Therefore, the IT suppliers and end users have created opportunities to exchange their knowledge and competencies needed for joint information system development. Tidd et al. [17] emphasize the unique characteristics of lead users, who are able to:

- recognize requirements early,

- be ahead of the market in identifying and planning new requirements, 
- expect special benefits due to their company market position and complementary assets,

- develop their own innovations and applications. Similarly, Cartlige introduced the informed customer (IC) concept [8]. Typical areas of involvement of ICs are:

- the alignment of business and IT plans and strategies,

- the development of business unit objectives and requirements for information systems,

- the establishment and co-ordination of user groups,

- the development and negotiation of SLRs and SLAs,

- managing the provision of the IT services,

- sharing the IT risk and gains.

In PRINCE2 project management methodology, the idea of Senior User represents the interests of all users, who will use the final products of the project, those for whom the product will achieve an objective, or those who will use the product to deliver benefits [14].

Barki and Hartwick proposed a distinction of user involvement from user participation. They define user participation as the assignments, activities and behaviours that users perform during the system development process. User involvement refers to the subjective psychological state reflecting the importance and personal relevance that a user attaches to a given system [1]. System designers have promoted techniques requiring user participation, such as prototyping, collaborative engineering, rapid application development and joint application design.

Collaborative engineering is an emerging approach to designing collaborative work practices for high value recurring tasks [13]. To implement a collaborative work practice, groups need to be trained or require facilitation support. A key requirement is the users' willingness to change. In the information system life cycle, the designers analyse the system and basing on design patterns derived from their expertise, they propose changes that are evaluated by the user community and then implemented. Involving end users in the development process requires end users and developers to communicate in a common language to identify and specify requirements as well as solutions. However, in collaborative engineering the end users are still dominated by the producer. They are still considered less experienced. However, they do not always behave in the same way. They are characterized by the following criteria:

- involvement in the information system development process: strongly involved or just watching and not very useful,

- environment: personal (home) users, worker (corporate, organizational, enterprise) users,
- frequency of use: occasional, frequent, extensive,

- software used: word editors, email, graphics, accounting,

- educational level: basic, intermediate, advanced,

- relationship: internal users (co-workers), external users (clients) [2].

Differentiation of expertise and experience of users creates the need to support them in the information system development process. Although help desk systems and computer user support provide IT services, the organizational strategy of user support often depends on the organization's size, type, functions, location, financial condition, people skills and competencies as well as on the goals of computer support services. A challenge that continually confronts user support staff is the need to develop an IT platform to enable software applications creation by users and for them.

\subsection{Participatory Design}

Passive users are oriented towards the observation and acceptance of other people's efforts. But partnership and participatory design have focused on the design of user applications or the corealisation of a more holistic composition of new and existing technologies and practices. Infrastructural design issues like programming languages, security and resource models do not seem to be in need of partnership and participatory design. According to Torpel et al. participatory design (PD) is about the direct participation of those whose working lives will change as a consequence of the introduction of a computer application [18]. PD is different from the product-oriented design, because it is an attempt to give users a better tool rather than automating the skills of workers. PD assumes that users are best to determine how to improve their work, and the designers should only be consultants.

In PD processes, the information communication technology (ICT) should be considered as processes in the context of workplaces and not as individual products. Although there are ICT difficulties for nontechnical people, PD is to provide the system developers to meet and understand the users and to give users a voice in the design process. Therefore, developers are asked to create an environment where users can feel free to express their ideas, and the developers should take supportive role, enabling users to utilize their knowledge in their decision making for the better task design. PD is usually realized through workshops where stakeholders communicate and share information on strategic goals and outcomes. 


\subsection{User Centred System Design}

User centred system design (UCSD) is a process focusing on usability throughout the entire development process and further throughout the system life cycle. The key principles of UCSD are as follows: user focus, active user involvement, evolutionary system development, simple design representations, prototyping, evaluation of use in a context, holistic design, process customization [12]. Active user involvement means that representative users should be directly involved, both in the development project and in related activities, such as organizational development and designing new work practices. User design representations and terminology are understood by all users and stakeholders, so they can fully appreciate the consequences of the design on their future use situation. Abstract notions, such as use case, UML diagrams or requirements specifications are not sufficient to give the users a concrete understanding of the future use situation. Therefore, prototypes must be used to visualize and evaluate ideas and design solutions in cooperation with the end users in a real context. The principles for UCSD can be used for explanation model analysis and communicating, business process development, assessment and customization, as well as for knowledge transfer and procurement support.

\subsection{User Centric Management}

User centric management (UCM) is a philosophy and an approach to business management that puts users first in all decision making. The approach is realized to ensure frictionless, easy and intuitive interactions between the company and its stakeholders [16]. The companies are under the strong influence of users critique provided online, therefore they carefully analyze their website content and distribute only what is not harmful for them, and on the other side, they create a certain environment for users to increase their personal satisfaction and software usability. User-centric management is to balance user goals, business goals and technical feasibility. The Internet technologies supporting users and business are characterized by six attributes i.e., modular construction of software components, their controlled interoperability, maintainability, updateability, scalability and high speed of loading.

\subsection{Actor Network Theory}

Actor network theory (ANT) was originally developed by Bruno Latour and Michael Callon to describe the creation and evolution of socio-technical networks and was further extended to focus on the dynamics of relationships among such actors and networks [5]. According to the theory, organizations are perceived as legal entities and constantly changing collections of people, objects, rules, ideas, strategies, legal representatives, and politics. Actors achieve their significance by being in relation to other entities. The ANT theory seems to be valuable to explain the role of user, who is perceived as the hub surrounded by business managers and IT people. The circumstances influence the user, and on the other side - the user creates the environment through his competencies.

The enterprise competencies are addressed at two levels: the enterprise level and the personal level. An enterprise competence is an integrated complex of enterprise skills, knowledge and technology. To a considerable extent, enterprise's competencies rest on the competencies of employees, i.e., the competencies at the personal level. Competencies are defined in measurable behavioural characteristics that determine the ability to function successfully knowledge, skills, craftsmanship, attitude, social skills, personal traits. They are also the abilities to cooperate, to take initiatives or show customerorientation and decision making skills.

\subsection{Customer Knowledge Management}

For many years mass production and product customization were business strategies that aimed at fulfilling individual needs quickly and efficiently. While increasingly demanding customers have prompted many producers to implement customer relationship management (CRM) strategies, there are research works proposing a conceptual framework about the internal processes involved in creating customer knowledge competences, which allow firms to customize product more efficiently and effectively. Modern CRM software packages include front office applications that access customer and product data as well as back office systems including data warehouses, financials, inventory and enterprise resource planning (ERP) systems. Customer knowledge management refers to processes that generate and integrate information about customers [7]. Customer knowledge management is recognized as a key strategic resources in any company's success as well as an integrated management approach and competence, an ongoing process of generating, disseminating and using customer knowledge within an organization and between an organization and its customers. Customer knowledge is generated and disseminated within the formal and informal meetings and discussions among employees from different departments, i.e., tacit. Individual customer knowledge is shared and turned into explicit organizational knowledge. 


\subsection{User Experience Design}

User experience (UX) design by Unger and Chandler is defined as a creation and synchronization of the elements that affect users' experience with a particular firm, with the intent of influencing their perceptions and behaviour [19]. Bernhaupt noticed that user experience includes a look on all the qualitative experience a user is making while interacting with a product, or on experiences made during interacting with a special type of product e.g., a mobile phone [3]. The current ISO 20101 definition of user experience covers a person's perception and the responses resulting from the use of a product, system, or service. For example, user experience in games is evaluated using a variety of concepts i.e., immersion, fun, presence, involvement, engagement, playability, and entertainment.

The concept of user experience is understood as the subjective relationship between user and application. It goes beyond the usability of the application, focusing on the personal outcome that the user gets from interacting with the application while performing a task [6]. In Human Computer Interaction (HCI), the term of experience design is about considering the user, the task and the context when designing a computer application [6]. Usually, the projects have a large context that the users should understand and IT people should integrate into their planning. This context is the project's ecosystem and it includes the environment, where IT users are working, the company culture, the general type of work they all will be engaged in and the people with whom they interact within their roles and responsibilities.

The UX design approach is to refer to the roles involved in understanding users and analysis, highlevel design of the system as experienced by the users, specification of system behaviour, high-level interaction, design and screen layout, and testing proposed or completed designs with users [4].

\subsection{Users as Innovators}

Users as innovator benefit from their positive experience that fulfils personal needs and interests. Designing for use and testing by use seem to be essential characteristics of user-innovators. They are motivated by their own desires for a better product. However, there is a risk that the user involvement in the design process will never be properly rewarded and an organization fails to provide a positive user experience, so the negative consequences can occur such as negative publicity and loss of user engagement. Therefore, only through the social interactions, perceived dialogue online, social accessibility, and transparency the value can be cocreated. Some initiatives have institutional background involving professional staff i.e., IT people, others are built on communities of practitioners and rely on their voluntary work. Therefore, knowledge repositories could be organized as a place to share and exchange resources. There are a couple of models of open collaborations [11]:

- user-producer model: centralized model, although real costs can be met with resources other than money, most initiatives need to raise some capital,

- co-production model: equal participation,

- the replacement model, open content replaces other uses and benefits from cost savings,

- the foundation, donation or endowment model in which funding for the project is provided by an external actor,

- the segmentation model, in which the provider offers value-added services to user segments and charges them for these services,

- the conversion model, in which "you give something away for free and then convert the consumer to a paying customer",

- membership model, voluntary support model, based on fund-raising campaigns or paying members [11].

User innovation begins when one or more users recognize a new set of design possibilities. Sometime after user innovation begins, the first user purchase appear i.e., user who wants to buy the goods that embody the user innovation rather than ordering them from professionals.

Websites such as Twitter, Facebook, MetaCafe, Wikipedia, Flickr among other have all been introduced within the last decade and rapidly grew in user membership. Di Gandi and Wasko believe that organizations are beginning to invest time and effort in developing a social media presence, to capitalize on a growing user population that is interested in creating and exploring the websites [10]. Organization perceives the opportunities to realize the potential benefits that can be captured when users and organizations co-create value. Perhaps organization could benefit from a large membership of users. On the other side, users benefit from a positive user experience that fulfils personal needs and interests.

\section{Empirical research on user involvement in system development}

The literature studies created the need to empirically verify that very optimistic attitude of academic publications' authors towards user involvement. Therefore, the empirical research was conducted in 2011. The research covered the interviews with Chief Information Officers (CIOs) from 270 firms in Poland. Characteristics of the surveyed firms are presented in Table 1. 
User involvement in this paper is considered as participation in the business information system development process measured as a set of activities that users have performed. In this research, CIOs answered the questions concerning the activities of users at their companies. Historically, there are several kinds of adaptive methods of information system development that build a model of users' knowledge and their involvement in that process. Active participation of a person in a community is a powerful indicator of the person's interests, preferences, beliefs and social and demographic context. Community members are a part of users' model and can contribute to tasks like personalized services, assistance and recommendations.

Table 1. Surveyed Companies Features

\begin{tabular}{|l|c|}
\hline Feature & $\mathbf{N}=\mathbf{2 7 0}$ \\
\hline Number of employees & \\
\hline Micro Enterprises (1-9 employees) & $44,4 \%$ \\
\hline Small Enterprises (10-49 employees) & $29,3 \%$ \\
\hline Medium Enterprises (50-250 employees) & $15,2 \%$ \\
\hline Big Companies (more than 250 employees) & $11,1 \%$ \\
\hline Dominating Activities & \\
\hline Production & $9,3 \%$ \\
\hline Commerce & $31,5 \%$ \\
\hline Services & $59,2 \%$ \\
\hline Main Clients & \\
\hline Individual & $61,1 \%$ \\
\hline Institutional & $38,9 \%$ \\
\hline
\end{tabular}

Involvement of the end users in IT projects covering IS development is presented in Table 2.

Table 2. Participation of Users in IT projects

\begin{tabular}{|c|c|c|c|c|c|c|}
\hline \multicolumn{7}{|c|}{ User } \\
\hline & $\begin{array}{c}\text { Pas- } \\
\text { sive }\end{array}$ & $\begin{array}{c}\text { Evalu- } \\
\text { ator }\end{array}$ & $\begin{array}{c}\text { Co- } \\
\text { creator }\end{array}$ & $\begin{array}{c}\text { Part- } \\
\text { ner }\end{array}$ & $\begin{array}{c}\text { Produ- } \\
\text { cer }\end{array}$ & $\begin{array}{c}\text { Prosu- } \\
\text { mer }\end{array}$ \\
\hline $\begin{array}{c}\text { GS } \\
\text { PC }\end{array}$ & $15 \%$ & $17 \%$ & $\mathbf{3 3 \%}$ & $24 \%$ & $10 \%$ & $1 \%$ \\
\hline $\begin{array}{c}\text { BLA } \\
\text { BPM }\end{array}$ & $\mathbf{3 2 \%}$ & $22 \%$ & $19 \%$ & $20 \%$ & $5 \%$ & $1 \%$ \\
\hline RE & $\mathbf{3 7 \%}$ & $19 \%$ & $17 \%$ & $16 \%$ & $10 \%$ & $1 \%$ \\
\hline ISD & $\mathbf{3 4 \%}$ & $20 \%$ & $19 \%$ & $15 \%$ & $10 \%$ & $1 \%$ \\
\hline ISI & $\mathbf{3 9 \%}$ & $16 \%$ & $19 \%$ & $15 \%$ & $9 \%$ & $1 \%$ \\
\hline IST & $18 \%$ & $20 \%$ & $\mathbf{2 4 \%}$ & $21 \%$ & $15 \%$ & $2 \%$ \\
\hline ISE & $22 \%$ & $\mathbf{2 7 \%}$ & $24 \%$ & $14 \%$ & $10 \%$ & $2 \%$ \\
\hline ISM & $20 \%$ & $23 \%$ & $\mathbf{2 4 \%}$ & $19 \%$ & $12 \%$ & $3 \%$ \\
\hline SIS & $\mathbf{3 3 \%}$ & $18 \%$ & $20 \%$ & $14 \%$ & $13 \%$ & $1 \%$ \\
\hline ISU & $7 \%$ & $23 \%$ & $20 \%$ & $\mathbf{3 0 \%}$ & $15 \%$ & $4 \%$ \\
\hline
\end{tabular}

In Table 2, the following activities of users have been specified: goal specification and project concepts (GSPC), business logic analysis and business process modelling (BLA BPM), requirements engineering (RE), information system design (ISD), information system implementation (ISI), information system testing (IST), information system installation and migration to a new IT environment (ISE), information system maintenance (ISM), security of information system (SIS), information system usage (ISU).

In Table 2, six different profiles of users have been included. Passive users and users-evaluators are oriented towards the observation and acceptance of other people's efforts for IT projects and business information system (BIS) development. Co-creator supports IT staff in the BIS design and implementation works. User as the partner plays equally important role as IT professionals in the system development process. User as the producer is self-dependent and self-organized and has got sufficient competencies to utilize IT independently of the IT staff help. Self-organization is the property of well-functioning complex systems that allows the relationships among individuals to shape the nature of an evolving group knowledge. The last i.e., prosumers are able to develop the BIS by themselves and utilize them for their work purposes and individual goals. Taking into account the results included in Table 2 you can notice that users are rather inactive. In this survey, CIOs evaluate users as inactive at business analysis and business process modelling stages as well as at requirements engineering, system design and implementation stages. IT people do not demand the technical expertise from users, but they should be helpful at the initial stages of business information system development process. Users were evaluated as cocreator in project concepts specification stage, information system testing and maintenance. Security of BIS is the domain of IT professionals. The strong activity of users is revealed in the business information system exploitation process.

Further analyses were realized separately for each of the groups included in Table 1. In micro and small companies users are assumed to have direct, informal and face-to-face (F2F) contact with IT staff, therefore they know more about requirements of each individual. In medium and big companies, the contact between the user and IT personnel is indirect, online and occasional, therefore the formal procedures of registration of user needs are implemented and the users have no chance to be personally involved in the BIS development process.

In the realized survey, the first question concerns the expected benefits and potential impediments. At big companies, over $70 \%$ of respondents admit that the most important benefits of user involvement in the BIS development process cover better understanding of user requirements (83.3\%), reduction of costs of research and development works (73.3\%), opportunities for market offer differentiation $(73.3 \%)$, and improvement of company image (over $70 \%$ ). Similarly at medium enterprises, over $70 \%$ of respondents argue that the most important benefits of end-user involvement in BIS development process comprise better understanding of user requirements (80.5\%), development of strong relationship with user $(80.5 \%)$, reduction of the cost of knowledge acquisition $(75.6 \%)$ and improvement of company image $(75.6 \%)$. 
At small companies, the most important benefits of user involvement in the BIS development include: supporting user education $(72.2 \%)$, better understanding of user requirements $(72.2 \%)$, taking better market position (67.1\%). At micro companies, the most important benefits of user involvement in the BIS development process comprise: better understanding of the user requirements (over 83\%), moving to the better market position (over $71 \%$ ), and improvement of company image (70\%). It should be noticed that CIOs do not perceive that user involvement is helpful to reduce IT product time to market.

The most important impediments of user involvement in the BIS development process comprise:

- at micro companies, user lack of knowledge and computer skills (73\% of respondents mention that), inevitability to learn new technologies $(66 \%)$, lack of incentives and encouragement from the BIS producer $(65 \%)$,

- at small companies, necessity to learn new technologies $(72 \%$ of respondents within this group state it), user lack of skills and knowledge $(71 \%)$ and user lack of incentives provided by BIS producers $(62 \%)$,

- at medium companies, user lack of knowledge and skills (according to $80 \%$ of respondents), necessity to learn new technologies $(68 \%)$, and the threat of theft of user ideas $(61 \%)$,

- at big companies, necessity to know new technologies $(80 \%)$, user lack of knowledge and skills $(73 \%)$, and lack of incentives provided by BIS producers $(57 \%)$.

At companies, mostly oriented towards corporate customers (business-to-business, B2B sector), the most important benefits of users' involvement into the BIS development process are as follows:

- better understanding of customer needs (83\%),

- improvement of corporate image $(80 \%)$,

- personal satisfaction of users $(83 \%)$,

- opportunity to learn new IT products $(80 \%)$. At companies, mostly oriented towards individual customers (business-to-customer, B2C sector) the important benefits of users' involvement are following:

- better understanding of user needs (73\%),

- opportunity to get business knowledge in a low cost way $(67 \%)$,

- improvement of corporate image (66\%).

The most important impediments of user involvement in the BIS development process comprise:

- user lack of knowledge and skills (at B2B companies $76 \%$ of respondents mentioned it, and respectively at $\mathrm{B} 2 \mathrm{C}$ companies - 67\%),

- obligation to learn new IT products and technologies (at B2B companies $65 \%$ of respondents argue that, and at $\mathrm{B} 2 \mathrm{C}$ companies $67 \%$ ),

- lack of incentives and encouragement from the BIS producers to support user activation (52\% of responses at $\mathrm{B} 2 \mathrm{~B}$ companies, and $67 \%$ - at $\mathrm{B} 2 \mathrm{C}$ firms).

The second question in this survey concerns methods of user activation to encourage them to the cooperation for BIS development. So, in the survey the following methods have been identified:

- at big companies, participation of users in trainings, courses and workshops $(90 \%$ of respondents emphasize that), constant discussions of IT personnel with users $(86.7 \%)$ and participation of users in reviewing processes covering interfaces reviews and use case analyses $(77 \%)$,

- at medium companies, participation of end-users in BIS testing (indicated by $90 \%$ of respondents), constant discussions of IT staff with users $(85 \%)$, and user involvement into the quality management team work $(76 \%)$,

- at small companies, participation of users in trainings, courses and workshops $(75 \%$ of respondents answered that), constant discussions of IT personnel with users $(72 \%)$ and occasional interviews and meetings with users( $72 \%)$,

- at micro companies, interviews and meetings of IT staff with users $(75 \%)$, participation of users in trainings, courses and workshops (73\%), user involvement into the quality management team works (71\% of respondents), and distribution of free and open source software $(70 \%)$.

None of the respondent groups emphasize agile methods application for software development or for project management. IT personnel and users are observed as conservatively minded persons. Similarly, the corporate architecture model discussions as well as IT product customisation opportunities have not been perceived as valuable for user encouragement. Beyond that, users are not interested in the control and evaluation of BIS administrator works.

At the B2C companies the following user activation methods have been considered as the most important:

- interviews and discussions with users (72\%),

- participation of users in trainings, courses and workshops (75\%),

- distribution of freeware and demo versions of software tools and business applications (69\%),

- user participation in software testing during prototyping or pilot version implementation $(69 \%)$,

At the B2B companies the CIOs as survey respondents emphasized the following users' activation methods: 
- interviews and constant discussion of IT staff with users $(82 \%)$,

- participation of users in software testing (81\%),

- presentation of UML use cases to enable and support users in the process of the BIS construction understanding (81\%),

- presentation of screen layouts of business application to discuss with users the software usability $(78 \%)$,

- participation of users in trainings, courses and workshops (81\%).

The third question concerns the usability of virtual communities as well as social media for BIS development. The controversial opinion results are presented in the Tables 3-6.

Table 3. Virtual Community and Social Media at Micro Companies - IT personnel attitude [\%]

\begin{tabular}{|c|c|c|c|c|c|}
\hline \multirow{2}{*}{ Media } & \multicolumn{5}{|c|}{ For high quality of BIS } \\
\cline { 2 - 6 } & $\boldsymbol{C}$ & $\boldsymbol{R}$ & $\boldsymbol{N}$ & $\boldsymbol{U}$ & $\boldsymbol{I}$ \\
\hline Newsletters & 14 & 29 & $\mathbf{4 2}$ & 13 & 2 \\
\hline Company staff blogs & 13 & 34 & $\mathbf{4 2}$ & 10 & 1 \\
\hline Users' blogs & 9 & 29 & $\mathbf{5 1}$ & 10 & 1 \\
\hline Facebook & 11 & 26 & $\mathbf{5 2}$ & 8 & 3 \\
\hline Twitter & 8 & 24 & $\mathbf{5 7}$ & 9 & 2 \\
\hline ITproduct sale portals & 9 & 32 & $\mathbf{4 4}$ & 13 & 2 \\
\hline $\begin{array}{c}\text { IT product exploitation } \\
\text { portals }\end{array}$ & 9 & 35 & $\mathbf{4 6}$ & 9 & 1 \\
\hline Social networking & 9 & 23 & $\mathbf{5 2}$ & 14 & 2 \\
\hline Chat room & 6 & 18 & $\mathbf{6 2}$ & 13 & 1 \\
\hline
\end{tabular}

Table 4. Virtual Community and Social Media at Small Companies - IT personnel attitude [\%]

\begin{tabular}{|c|c|c|c|c|c|}
\hline \multirow{2}{*}{ Media } & \multicolumn{5}{|c|}{ For high quality of BIS } \\
\cline { 2 - 6 } & $\boldsymbol{C}$ & $\boldsymbol{R}$ & $\boldsymbol{N}$ & $\boldsymbol{U}$ & $\boldsymbol{I}$ \\
\hline Newsletters & 19 & 32 & $\mathbf{3 8}$ & 10 & 1 \\
\hline Company staff blogs & 11 & 38 & $\mathbf{4 3}$ & 6 & 2 \\
\hline Users' blogs & 14 & 33 & $\mathbf{4 0}$ & 9 & 4 \\
\hline Facebook & 19 & 23 & $\mathbf{3 5}$ & 19 & 4 \\
\hline Twitter & 17 & 16 & $\mathbf{4 3}$ & 22 & 2 \\
\hline ITproduct sale portals & 14 & $\mathbf{3 6}$ & 39 & 17 & 4 \\
\hline $\begin{array}{c}\text { IT product } \\
\text { exploitation portals }\end{array}$ & 18 & $\mathbf{3 7}$ & 30 & 15 & 0 \\
\hline Social networking & 19 & 28 & $\mathbf{3 2}$ & 15 & 6 \\
\hline Chat room & 13 & 29 & $\mathbf{4 3}$ & 10 & 5 \\
\hline
\end{tabular}

The IT staff representatives were asked if the virtual communities and new media are important for high quality of business information systems. Their opinions were distinguished as:

- compulsory (C): the Internet solution is necessary to ensure a high quality of BIS,
- required $(\mathrm{R})$ : the proposed solution seems to be required, but not so strongly demanded as above,

- neutral $(\mathrm{N})$ : the solution is indifferent to the BIS development and without impact on it,

- useless (U): the Internet solution is superfluous for BIS development,

- impediment (I): the solution is harmful and detrimental for the BIS development (i.e., design, implementation and exploitation).

Table 5. Virtual Community and Social Media at Medium Companies - IT personnel attitude [\%]

\begin{tabular}{|c|c|c|c|c|c|}
\hline \multirow{2}{*}{ Media } & \multicolumn{5}{|c|}{ For high quality of BIS } \\
\cline { 2 - 6 } & $\boldsymbol{C}$ & $\boldsymbol{R}$ & $\boldsymbol{N}$ & $\boldsymbol{U}$ & $\boldsymbol{I}$ \\
\hline Newsletters & 14 & 32 & $\mathbf{4 2}$ & 12 & 0 \\
\hline Company staff blogs & 12 & $\mathbf{4 4}$ & 37 & 7 & 0 \\
\hline Users' blogs & 12 & $\mathbf{4 2}$ & 29 & 15 & 2 \\
\hline Facebook & 12 & 22 & $\mathbf{5 4}$ & 12 & 0 \\
\hline Twitter & 10 & 19 & $\mathbf{6 1}$ & 10 & 0 \\
\hline ITproduct sale portals & 7 & 24 & $\mathbf{5 1}$ & 15 & 3 \\
\hline $\begin{array}{c}\text { IT product exploitation } \\
\text { portals }\end{array}$ & 10 & 37 & $\mathbf{3 9}$ & 12 & 2 \\
\hline \begin{tabular}{c} 
Social networking \\
\hline Chat room
\end{tabular} & 10 & 29 & $\mathbf{4 6}$ & 13 & 2 \\
\hline
\end{tabular}

Table 6. Virtual Community and Social Media at Big Companies - IT personnel attitude [\%]

\begin{tabular}{|c|l|l|l|l|l|}
\hline \multirow{2}{*}{ Media } & \multicolumn{5}{|c|}{ For high quality of BIS } \\
\cline { 2 - 6 } & $\boldsymbol{C}$ & $\boldsymbol{R}$ & $\boldsymbol{N}$ & $\boldsymbol{U}$ & $\boldsymbol{I}$ \\
\hline Newsletters & 13 & $\mathbf{4 1}$ & 40 & 3 & 3 \\
\hline Company staff blogs & 13 & 20 & $\mathbf{5 7}$ & 7 & 3 \\
\hline Users' blogs & 13 & 34 & $\mathbf{4 3}$ & 10 & 0 \\
\hline Facebook & 17 & 17 & $\mathbf{4 7}$ & 16 & 3 \\
\hline Twitter & 13 & 17 & $\mathbf{5 0}$ & 17 & 3 \\
\hline $\begin{array}{c}\text { ITproduct sale } \\
\text { portals }\end{array}$ & 14 & 23 & $\mathbf{4 7}$ & 13 & 3 \\
\hline $\begin{array}{c}\text { IT product } \\
\text { exploitation portals }\end{array}$ & 20 & 30 & $\mathbf{3 4}$ & 13 & 3 \\
\hline Social networking & 20 & 27 & $\mathbf{4 0}$ & 13 & 0 \\
\hline Chat room & 13 & 17 & $\mathbf{5 7}$ & 7 & 6 \\
\hline
\end{tabular}

Tables 3-6 include the percentage of positive responses in each of the 4 companies groups. The presented in Tables 3-6 information reverses the theory concerning very positive acceptance and necessity to develop virtual communities and social media implementation for BIS development. Mostly, the new media solutions for the B2B as well as for B2C companies are treated as required and neutral, but they are not necessary.

The IT staff (represented in the survey by CIOs) is able to tolerate the mentioned in Tables 3-6 solutions i.e., newsletters, company staff blogs, users' blogs, Facebook and Twitter presences, IT 
product sale and exploitation portals, social networking and chat room, but they do not admit that the mechanisms are valuable for BIS implementation and exploitation.

The last question asked for this survey concerned attitudes of users towards traditional solutions implemented for their support i.e., customer relationship management (CRM) systems, in-house and outsourced help desk, IT service anticipation systems and providing the consultancy by CIOs. The user support mechanisms are considered as required. The results are visible in Tables 7-10.

Table 7. Acceptance of User Support Applications at Micro Companies - IT personnel attitude [\%]

\begin{tabular}{|c|c|c|c|c|c|}
\hline \multirow{2}{*}{ Media } & \multicolumn{5}{|c|}{ For high quality of BIS } \\
\cline { 2 - 6 } & $\boldsymbol{C}$ & $\boldsymbol{R}$ & $\boldsymbol{N}$ & $\boldsymbol{U}$ & $\boldsymbol{I}$ \\
\hline Analytical CRM & 13 & $\mathbf{4 2}$ & 40 & 5 & 0 \\
\hline Transactional CRM & 20 & $\mathbf{4 3}$ & 34 & 2 & 1 \\
\hline Operational CRM & 13 & $\mathbf{4 8}$ & 29 & 8 & 3 \\
\hline $\begin{array}{c}\text { Online insourced help } \\
\text { desk }\end{array}$ & 14 & $\mathbf{4 9}$ & 29 & 8 & 0 \\
\hline $\begin{array}{c}\text { Online outsourced help } \\
\text { desk }\end{array}$ & 10 & $\mathbf{4 4}$ & 40 & 6 & 0 \\
\hline $\begin{array}{c}\text { User Requirement } \\
\text { Forecasting system }\end{array}$ & 13 & 38 & $\mathbf{4 1}$ & 8 & 1 \\
\hline $\begin{array}{c}\text { CIO department for } \\
\text { users }\end{array}$ & 13 & 38 & $\mathbf{3 9}$ & 10 & 0 \\
\hline
\end{tabular}

For the surveyed companies, the presented in Tables 7-10 user support systems are considered as required, but they are not compulsory. In Tables 7-10 the following categories of user support software applications were distinguished:

- Analytical CRM system, covering user knowledge databases and data warehouses, enabling data mining, concluding on the user experiences and requirements, and recommending them the necessary trainings and workshops,

- Transactional CRM system, enabling IT services registration and management, service level management covering requirement level agreement (RLA) and service level agreement (SLA) negotiations,

- Operational CRM systems, implemented to register all possible contacts with users by phones, emails and mobile devices, as well as F2F meetings,

- Online in-house help desk, developed and maintained internally by IT staff for corporate internal (e.g., employees) and external (i.e., Internet customers) users,

- online outsourced help desk to ensure IT services for internal and external users,

- information system for forecasting the users' needs basing on their actual usage of the business applications,
- establishing the CIO office for development of the formal procedures of user support

Table 8. Acceptance of User Support Applications at Small Companies - IT personnel attitude [\%]

\begin{tabular}{|c|c|c|c|c|c|}
\hline \multirow{2}{*}{ Media } & \multicolumn{5}{|c|}{ For high quality of BIS } \\
\cline { 2 - 6 } & $\boldsymbol{C}$ & $\boldsymbol{R}$ & $\boldsymbol{N}$ & $\boldsymbol{U}$ & $\boldsymbol{I}$ \\
\hline Analytical CRM & 32 & $\mathbf{3 4}$ & 29 & 4 & 1 \\
\hline Transactional CRM & 20 & $\mathbf{6 1}$ & 15 & 3 & 1 \\
\hline Operational CRM & 22 & $\mathbf{5 6}$ & 20 & 1 & 1 \\
\hline $\begin{array}{c}\text { Online insourced help } \\
\text { desk }\end{array}$ & 23 & $\mathbf{5 3}$ & 22 & 1 & 1 \\
\hline $\begin{array}{c}\text { Online outsourced help } \\
\text { desk }\end{array}$ & 20 & $\mathbf{4 8}$ & 27 & 4 & 1 \\
\hline $\begin{array}{c}\text { User Requirement } \\
\text { Forecasting system }\end{array}$ & 39 & $\mathbf{3 4}$ & 20 & 4 & 3 \\
\hline $\begin{array}{c}\text { CIO department for } \\
\text { users }\end{array}$ & 17 & $\mathbf{5 2}$ & 20 & 10 & 1 \\
\hline
\end{tabular}

Table 9. Acceptance of User Support Applications at Medium Companies - IT personnel attitude [\%]

\begin{tabular}{|c|c|c|c|c|c|}
\hline \multirow{2}{*}{ Media } & \multicolumn{5}{|c|}{ For high quality of BIS } \\
\cline { 2 - 6 } & $\boldsymbol{C}$ & $\boldsymbol{R}$ & $\boldsymbol{N}$ & $\boldsymbol{U}$ & $\boldsymbol{I}$ \\
\hline Analytical CRM & $\mathbf{3 9}$ & 34 & 27 & 0 & 0 \\
\hline Transactional CRM & 24 & $\mathbf{3 9}$ & 37 & 0 & 0 \\
\hline Operational CRM & 32 & 29 & $\mathbf{3 9}$ & 0 & 0 \\
\hline $\begin{array}{c}\text { Online insourced help } \\
\text { desk }\end{array}$ & $\mathbf{4 2}$ & 34 & 24 & 0 & 0 \\
\hline $\begin{array}{c}\text { Online outsourced help } \\
\text { desk }\end{array}$ & 22 & $\mathbf{2 9}$ & $\mathbf{2 9}$ & 15 & 5 \\
\hline $\begin{array}{c}\text { User Requirement } \\
\text { Forecasting system }\end{array}$ & 22 & $\mathbf{3 9}$ & 37 & 2 & 0 \\
\hline $\begin{array}{c}\text { CIO department for } \\
\text { users }\end{array}$ & 22 & 32 & $\mathbf{4 1}$ & 5 & 0 \\
\hline
\end{tabular}

Table 10. Acceptance of User Support Applications at Big Companies - IT personnel attitude [\%]

\begin{tabular}{|c|c|c|c|c|c|}
\hline \multirow{2}{*}{ Media } & \multicolumn{5}{|c|}{ For high quality of BIS } \\
\cline { 2 - 6 } & $\boldsymbol{C}$ & $\boldsymbol{R}$ & $\boldsymbol{N}$ & $\boldsymbol{U}$ & $\boldsymbol{I}$ \\
\hline Analytical CRM & 27 & $\mathbf{4 7}$ & 23 & 3 & 0 \\
\hline Transactional CRM & 27 & $\mathbf{3 7}$ & 36 & 0 & 0 \\
\hline Operational CRM & 23 & $\mathbf{5 4}$ & 23 & 0 & 0 \\
\hline $\begin{array}{c}\text { Online insourced help } \\
\text { desk }\end{array}$ & $\mathbf{3 7}$ & 36 & 27 & 0 & 0 \\
\hline $\begin{array}{c}\text { Online outsourced help } \\
\text { desk }\end{array}$ & 20 & $\mathbf{4 3}$ & 27 & 10 & 0 \\
\hline $\begin{array}{c}\text { User Requirement } \\
\text { Forecasting system }\end{array}$ & 30 & $\mathbf{4 0}$ & 30 & 0 & 0 \\
\hline $\begin{array}{c}\text { CIO department for } \\
\text { users }\end{array}$ & 30 & $\mathbf{3 7}$ & 30 & 0 & 3 \\
\hline
\end{tabular}

For the companies, the presented in Tables 7-10 user support systems are considered by the respondents as required, but not compulsory solutions. Generally, CIOs argue that proposed user support applications are positively accepted, there are no opinions that presented systems are impediments. The CIOs perceive that CRM systems, particularly analytical CRM systems are helpful to 
recognize the unique user requirements and encourage them into the BIS development activities.

The perception of usefulness of CRM systems is similar in different size companies. The very positive attitude towards user support systems suggest that user knowledge management approach could be further developed basing just on the analytical CRM systems.

\section{Conclusion}

Literature studies lead to the conclusion that business organizations are beginning to realize the potential benefits that can be captured when users and IT people co-create values. So far, different methods have been developed to strongly involve users in the BIS development. Methods i.e., collaborative engineering, participatory design, UCSD, customer knowledge management, user experience design are based on the assumption that users must be pulled into action and they must be encouraged to reveal their requests. On the other side, approaches i.e., user-centric management, actor-network theory, user as innovator emphasize the central and active role of users.

In many cases, companies are not conscious of the opportunities and potential benefits that could be realized if the users would be more active and involved in the BIS development and exploitation processes. Companies perceive some benefits from a wide cooperation with users. They get benefits such as marketing insights, cost savings, brand awareness and idea generation. User benefits from the fulfillment of personal needs, opportunities to get new knowledge and satisfaction, because of doing something for themselves.

In the survey done in 270 firms, the CIOs or IT professionals have been observed as very skeptical about the usability of new media and social networking for the business application development. Although in the Internet, there are several examples of positive attitudes towards new media, business managers consider new media e.g., Twitter as useless and unnecessary disturbances.

The research revealed important problems of lack of skills and knowledge of users as well as lack of incentives necessary for their involvement in the BIS development. Therefore, a huge social capital is unused and development of user knowledge codification and management would be needed.

The future research will cover the analysis of prerequisites for decentralized management and architecture modeling of end user applications. Particularly, huge opportunities are hidden in cloud computing, which is a new way of IT services' distribution and a new way of business application user activity.

\section{Acknowledgement}

The work is funded by the National Science Centre in Poland. The grant number is 4100/B/H03/2011/40.

\section{References}

[1] Barki, H. and Hartwick, J. (1994) 'Rethinking the concept of user involvement, and user attitude', MIS Quarterly, 18(1), pp. 59-79.

[2] Beisse, F. (2010) A Guide to Computer user support for help desk and support specialist, Course Technology, Cengage Learning, Boston.

[3] Bernhaupt, R. (2010) 'User Experience Evaluation in Entertainment', in Evaluating User Experience in Games, Concepts and Methods, Bernhaupt, R., (ed) Springer-Verlag, London, pp. 3-10.

[4] Beyer, H. (2010) User-Centered Agile Methods, Morgan \& Claypool Publishers, Boston.

[5] Callon, M., Latour, B. (1981) 'Unscrewing the Big Leviathan: How Actors Macro-Structure Reality and How Sociologists Help Them to Do So', in Advances in Social Theory and Methodology: Towards an Integration of Micro and Macro-Sociologies, KnorrCetina, K.D, and Cicourel, A.V., (eds), London, Routledge and Kegan Paul, pp. 277-203.

[6] Calvillo-Gamez, E.H., Cairns, P., and Cox, A.L. (2010) 'Assessing the Core Elements of the Gaming Experience' in Evaluating User Experince in Games, Concepts and Methods, Bernhaupt, R., (ed.), Springer, London, pp. 47-72.

[7] Campbell, A.J. (2003) 'Creating customer knowledge competence: managing customer relationship management programs strategically' in Industrial Marketing Management, 32, pp. 375-383.

[8] Cartlidge, A. (2004) Best Practice for Business Perspective: The IS View on Delivering Services to the Business, ITIL, the key to Managing IT services. TSO, Norwich.

[9] Claycomb, C., Lengnick-Hall, C.A., and Inks, L.W. (2001) 'The customer as a productive resource: A pilot study and strategic implications', in Journal of Business Strategies, 18(1), pp. 47-69.

[10] Di Gangi, P.M., Wasko, M. (2009) 'The Co-Creation of Value; Exploring User Engagement in UserGenerated Content Websites' in Proceedings of JAIS Theory Development Workshop, Sprouts: Working Papers on Information Systems 9(50) http://sprouts.aisnet.org/9-50.

[11] 'Giving Knowledge for Free, The emergence of open education resources, Centre for educational reserach and innovation' (2007) Organisation for economic co-operation and development, OECD, Paris, retrieved: May $2011 \mathrm{http} / / / \mathrm{www}$. oecd.org/document/ 41/0,3343,en_2649_35845581_38659497_1_1_1_1, 00.html,.

[12] Gulliksen, J., Goransson, B., Boivie, I., Persson, J., Blomkvist, S., Cajander, A. (2005) 'Key principles for user-centered systems design', in Humancentered software engineering - integrating usability in the software development lifecycle, Seffah, A., 
Gulliksen J., Desmarais, M.C. (eds.) Springer, Berlin, pp. 17-37.

[13] Kolfschoten, G.L., Briggs, R.O, de Vreede, G.J. (2010) 'A technology for Pattern-Based Process Design and its Application to Collaboration Engineering' in Collaborative technologies and applications for interactive information design, emerging trends in user experiences, Rummler, S. Bor, N.G.K. (eds) Information Science Reference, Hershey, NY, pp. 1-19.

[14] Pieper, M. and van Bon, J. (2005) Project Management Based on PRINCE2, Van Haren Publishing, Zaltbommel.

[15] Prahalad, C.K. and Ramaswamy, V. (2000) 'Coopting customer competence' in Harvard Business Review, 78(1), pp. 79-87.

[16] Shapiro, A. (2011) Users not Customers, Penquin Books Ltd. London.

[17] Tidd, J., Bessant, J., and Pavitt, K. (2005) Managing innovation, Integrating technological, market and organizational change, 3rd Edition, John Wiley and Sons, Chichester.

[18] Torpel, B., Voss, A., Hartswood, M., and Procter, R. (2009) 'Participatory Design: Issues and Approaches in Dynamic Constallations of Use, Design and Research' in Configuring User-Designer Relations, Voss, A., Hartswood, M., Procter, R., Rouncefield, M., Slack, R.S., Buscher, M. (eds.), London, Springer Verlag, pp.13-30.

[19] Unger, R., ,Chandler, C. (2009) 'A Project Guide to UX Design For User Experience designers in the field or in the making', Peachpit Press, Berkeley.

[20] Von Hippel, E. (1986) 'Lead users: A Source of Novel Product Concepts' in Management Science, 32, 7, pp.791-805. 